\title{
Sobre amizade e admiração (Depoimento)
}

Silviano Santiago*

O livro Puerto Rican voices in English, habilmente estruturado por Carmen Dolores Hernández, oferece uma série de relatos autobiográficos que demonstram que a literatura transita por tempos e espaços diversos, para os quais é ao fim contraditório imaginar uma cultura autossuficiente situada num único território, enquanto desmente qualquer ilusão de uma "integração" fácil à cultura norte-americana.

No saber institucionalizado nas universidades dos Estados Unidos, o lugar de Porto Rico é muito incerto. Como não é nem "latinoamericano" nem "norte-americano", termina por borrar-se. [...] A exclusão tem sido a norma. Arcadio Díaz-Quiñones, A memória rota, pp. 99 e 237, respectivamente.

Quando da publicação em português dos ensaios do professor e crítico porto-riquenho Arcadio Díaz-Quiñones, seus amigos e colegas cariocas decidiram organizar na Livraria da Travessa, no Leblon, uma mesa-redonda em sua homenagem. Na cidade em que ele raramente pôs os pés, todos queriam acolhê-lo do modo como ele gentil e fraternalmente os acolhia em Princeton, New Jersey. Queriam também comentar e adquirir A memória rota (Companhia das Letras, 2016), antologia organizada e traduzida por Pedro Meira Monteiro, seu colega de Departamento na Universidade de Princeton. Por coincidência, Pedro estaria a trabalho no Rio de Janeiro na data aprazada.

Ao receber o convite para participar da mesa-redonda, dei-me conta de que - quando eu estivesse aboletado lá no estrado e a observar as pessoas

\footnotetext{
* Silviano Santiago nasceu em 1936, em Formiga (MG). Sua vasta obra inclui romances, contos, ensaios literários e culturais. Doutor em Letras pela Sorbonne, começou a carreira lecionando nas melhores universidades norte-americanas. Transferiu-se posteriormente para a PUC-Rio e é, hoje, professor emérito da UFF. Seu último romance, Machado (2016), recebeu o Prêmio Jabuti de Melhor romance e Melhor livro do Ano. E-mail: silviano.santiago@gmail.com.
} 
presentes - estaria fazendo parte de um grupo seleto de profissionais a que por direito não pertenço. Apesar de ter ensinado em diversas universidades norte-americanas, nossos caminhos nunca se cruzaram. Não pertencia, portanto, ao grupo dos bons amigos e das boas amigas cariocas (de nascimento ou por adoção, pouco importa) de Arcadio. De antemão, julguei esdrúxulo meu protagonismo em cerimônia tão simbólica e festiva. Por sincera e legítima autocrítica, considero-me mau protagonista e pior ator.

Simplesmente, não entendia o motivo do convite para a participação na mesa-redonda. Recusei-o com delicadeza.

O autor do convite, André Botelho, pediu-me que ponderasse. "Há outra e forte razão", me disse, "para o convite. Razão menos centrada na amizade que colegas cariocas mantêm com o convidado porto-riquenho. Penso", argumentou ele, "numa razão mais direcionada pelo que Arcadio representa nos ensaios reunidos, na docência em universidade norteamericana e, principalmente, no engajamento político na vida educacional e cotidiana dos seus compatriotas, imigrantes nos Estados Unidos da América".

Fiquei de ponderar e de dar a resposta definitiva noutro dia. Combinamos: até lá, a terceira cadeira no estrado estaria sem ocupante. Que ele se sentisse livre para melhor escolha.

Tento detalhar o que se passou durante o período de dúvida e de reflexão. Vai parecer mais longo do que foi na realidade. Isso porque - em apoio à minha in/decisão - terei de discorrer sobre matéria de caráter pessoal que, naquela noite festiva, serviu para abonar (encontrei afinal o verbo) minha presença à mesa, ao lado do autor dos ensaios e do seu amigo André Botelho. Gosto de jogar às claras. Exposta oralmente, a matéria pessoal talvez possa ter algum interesse quando exposta em revista acadêmica. Se me alongo, ponha-se menos a culpa no caro André e mais na amiga e colega Helena Bomeny, autora de segundo e posterior convite. Helena quis que eu substantivasse em escrita o teor oral do depoimento. Obedeço-lhe.

Vamos a ele.

Iniciei o depoimento dizendo que me sentia como que de volta à juventude belo-horizontina, quando - solitário nas agrestes e montanhosas Gerais açulava o desejo de participar de - de me inserir em grupos geracionais contemporâneos (a que não pertencia de direito) que estreitavam os laços literários ou culturais com o abraço afetuoso e amigo. Por razões que não vêm ao caso, não havia como libertar-me da maldição que carreia o título 
de filme interpretado por Jack Nicholson, "um estranho no ninho". Meu fado, minha sorte. Uma foto dos anos 1950, que tinha recebido dos irmãos Haroldo e Augusto de Campos, me socorreu no passado e hoje volta a me socorrer. Nela, os dois poetas paulistas se abraçam a um terceiro, Décio Pignatari. Revejo-a mentalmente e relembro os versos escritos por Décio e dedicados a Haroldo e a Augusto, e - por supuesto, já que se tratava de estreitar os laços dos três - também a ele próprio, terceira pétala da "rosa d'amigos" concretista. Copio a estrofe e deslindo o encantamento mágico daquela noite festiva da amizade, na Livraria da Travessa:

\author{
Esta é a rosa d'amigos (dirás: redonda) \\ E o outro: É o Teatro Chinês \\ Com sua placa de argila \\ Onde a efígie se grava \\ Entre sonhos perenes \\ De rosas imortais.
}

Gosto de jogar às claras, afirmei antes. Disse ao André que não poderia considerar-me amigo do Arcadio. Aliás, o prefácio à tradução dos ensaios é prova cabal: libera aos olhos de qualquer leitor a imagem viva duma "rosa d'amigos" brasileiros de Arcadio, rosa de mil e uma pétalas que, por décadas, vem sendo cultivada no campus da Universidade de Princeton, ou, para ser mais exato, nos departamentos com disciplinas que mantêm estreita ligação com o nosso Brasil. Um estranho no ninho - sem dúvida.

Não era amigo (no sentido preciso e poético do termo) do Arcádio, mas desde o mês de setembro de 1962, quando deixei a condição de bolsista e doutorando na Sorbonne e fui ser professor concursado na Universidade do Novo México, em Albuquerque, fora bom amigo de muitos dos nossos irmãos hispano-americanos, grupo amplíssimo de acadêmicos e também de não acadêmicos (meros cidadãos norte-americanos, ou imigrantes), um grupo generoso a que dupla e legitimamente pertence Arcadio. Quando em 1964 me transferi de Albuquerque (New Mexico) para New Brunswick (New Jersey) e fui ensinar na Universidade Rutgers, transformei o afeto que me levara a manter relações amistosas com os descendentes de mexicanos, os chicanos, em moeda corrente na minha vida acadêmica e cotidiana na costa leste dos Estados Unidos.

Com a mesma disponibilidade sentimental dos dois anos anteriores, mas de posse de maior conhecimento da experiência do que significa ser latino 
numa nação WASP, eu me aproximei dos porto-riquenhos e dos caribenhos, e dentro destes, dos dominicanos. A seu jeito e maneira, o estranho foi-se acomodando no ninho.

Disse, então, a André que só poderia sentar-me à mesa na Livraria da Travessa se retomasse, nas profundezas das suas raízes novo-mexicanas, um antigo e saudoso sentimento de amizade aos latinos. Pela admiração a um acadêmico porto-riquenho competente e engajado, eu revelaria a amizade que mantive e mantenho por um coletivo comunitário oprimido. Sentimento que sempre norteou meus passos no dia adia da vida universitária, ainda que noutra e diferente nação. Admirava e admiro todos os profissionais que, por uma razão ou outra, são capazes de ir além da pesquisa própria e original, ir além da difusão do saber disciplinar, a fim de atrair e angariar o interesse da população ianque ou das instituições norte-americanas para os que delas necessitam, mas não as merecem pelo próprio valor.

Minha amizade a Arcadio ${ }^{1}$, disse a André, se revelaria - no depoimento oral - por variadas e interpostas pessoas. Sob a bandeira da admiração aos latinos, ela ganharia a forma e o conteúdo do nobre sentimento de amizade.

Sentado à mesa no pequeno auditório da Livraria da Travessa, no Leblon, eu pertenceria ao grupo de amigas e amigos de Arcadio. Eu seria o admirador.

Recalquei os versos da "rosa d'amigos", signée pelos poetas concretos, e me aboletei nas Poesias Completas do pernambucano/carioca Manuel Bandeira, prefaciadas pelo casal Gilda e Antonio Candido de Mello e Souza. Assumi poemas e versos de Bandeira para - carioca e mineiramente - poder saudar com admiração o homenageado porto-riquenho da noite, Arcadio Díaz-Quiñones. Copio alguns versos de Flag, como Gilberto Freire o chamava carinhosamente:

Louvo o Padre, louvo o Filho,

O Espírito Santo louvo.

Isso feito, louvo aquele

Que ora chega ao Rio de Janeiro

E no meio dos seus pares

Prima pela qualidade.

\footnotetext{
${ }^{1}$ Cf.: "Princeton, como Porto Rico, é para mim um lugar de amizades e afetos muito intensos, e de um longo diálogo com colegas, alunas e alunos que me inspiraram e me ensinaram muito" (A memória rota, p. 273).
} 
Quem lhes fala não é amigo de Arcadio. Se o fosse, teria tido direito à palavra na vida acadêmica de Princeton e no prefácio ao livro de ensaios. Teria ganhado legítimo direito ao assento nesse estrado. Quem lhes fala é o admirador. Quem lhes fala é o admirador do Arcadio que - por interpostas pessoas e situações, quase todas perdidas no espaço/tempo da vida e hoje reencontradas na memória/saudade da imaginação - pôde melhor compreender e apreender não só a riqueza e a precisão nas análises históricas e literárias de $A$ memória rota, como também a grandeza política e ideológica na beleza da escrita dos ensaios diligentemente reunidos e traduzidos pelo colega Pedro.

Ao assumir a fala da admiração, assaltam-me lembranças desengonçadas, anárquicas e fortes. Conto agora com a paciência e a simpatia dos leitores, assim como contei com a paciência e a simpatia dos ouvintes na Livraria da Travessa. Começo - como comecei - de maneira aleatória, embora precisa. Começo pela canção "Lamento borincano", que escutei primeiramente na voz de Daniel Santos, cantor de dicção metálica e compassada, semelhante à do nosso Miltinho, voz que depois foi perseguida nas vozes de Javier Solis (personagem do romance Stella Manhattan, onde canta seu hit maior, "Sombras"), de Chavela Vargas, cantante mejicana ressuscitada por Pedro Almodóvar em belos filmes, e, finalmente, de Caetano Veloso.

"Lamento boricano" era e é o hino nacional dos porto-riquenhos (boricuas) no exílio norte-americano e, pelo tema desenvolvido na letra, jorrou água em duas fontes da minha formação estrangeirada. Na antiga UFMG, os professores Rodrigues Lapa, de Literatura portuguesa, e Damien Saunal, de Francesa, dão-se as mãos.

Relembrava eu o Mofina Mendes, auto de Gil Vicente, e a fábula “La laitière et le pot au lait", de La Fontaine. Cito, primeiramente, cinco versos do "Lamento borincano". Neles se evidencia o tema do tópos - o sonho que leva o caipira a crer na melhoria do padrão de vida da família, se o pequeno negócio no campo render o necessário e o indispensável, e algo mais, no mercado público da cidade mais próxima:

Sale, loco de contento con su cargamento para la ciudad, jay! para la ciudad. Lleva en su pensamiento todo un mundo lleno de felicidad, jay! de felicidad. Piensa remediar la situación del hogar que es toda su ilusión así.

$Y$ alegre, el jibarito va cantando así, diciendo así, pensando así por el camino, si yo vendo la carga, mi Dios querido, un traje a mi viejita voy a comprar. 
O milagre da multiplicação dos pães e peixes, de que fala o Novo Testamento, lá está também na fábula de La Fontaine e no auto de Gil Vicente. Por ser menos conhecido, opto por citar Gil Vicente:

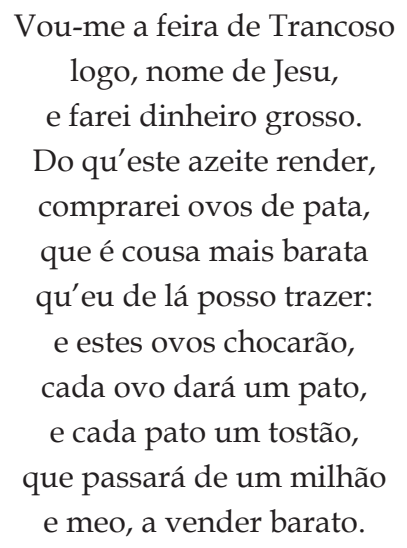

Disse-lhes que comecei a fala da admiração de modo aleatório e preciso. Na sua simplicidade, "Lamento borincano" fazia ressoarem minhas leituras acadêmicas em português e em francês, e tempos imemoriais. E tempos modernos e atualíssimos também. Abria os olhos do brasileiro afrancesado para a realidade que eles haviam visto no Novo México, a dos wet-backs, imigrantes que atravessavam o Rio Grande a nado, e a dos chicanos - los pachucos - aclimatados à agricultura na Califórnia. E os abria ainda para documentar o dia a dia dos porto-riquenhos e caribenhos na região leste dos Estados Unidos.

“O lamento borincano ganhava corpo e sangue nas primeiras incursões pelo pensamento anticolonial e pós-colonial em língua francesa, de que eram exemplo, para o neófito brasileiro em Paris, o Frantz Fanon de Peau noire, masque Blanc (1952), o Aimé Césaire do poema Cahier d'un retour au pays natal (1947) ou a revista Présence africaine (desde 1947). E ainda ganhavam reflexão nos surveys de literatura colonial brasileira que faziam parte do currículo de Literatura brasileira nas universidades em que ensina.

Ganham, ainda, escrita autobiográfica, sofrimento individual e coletivo, sentido e peso político e ideológico na leitura dos ensaios de A memória rota, de Arcadio, como o que expõe a justa e incontornável reflexão sobre o verbo bregar. Este verbo - Como vai a vida? Vou levando - substitui o milagre bíblico da multiplicação dos pães e dos peixes pela alta voltagem na apreensão de verbo banal e específico da fala popular dos porto-riquenhos 
que traduz as artimanhas do trabalho semiescravo nas grandes metrópoles. Ir levando a vida, ou bregar, traduz o milagre da sobrevivência.

Copio importante passagem da análise de Arcadio. Nela, ele avança a 'lógica do menos pior' (p. 44), prevalente no raciocínio sobre o cotidiano nas classes populares porto-riquenhas em Nova York:

Bregar é, poder-se-ia dizer, outra ordem de saber, um método difuso e sem alarde para navegar a vida cotidiana, onde tudo é extremamente precário, cambiante ou violento, como foi durante o século XX para as emigrações porto-riquenhas e o é hoje, em todo o território da ilha (p. 38).

Bregar - acrescenta Arcadio posteriormente - 'designa o que é 'manejável' com a destreza das mãos reais ou simbólicas'.

No auto de Gil Vicente, na fábula de La Fontaine e na canção do portoriquenho Rafael Hernández, é forte a alegria decorrente do sonho de vida familiar mais confortável e prazerosa, que é apenas momentânea. O ganho com o trabalho duro leva o sonhador ao pulo pouco precavido - e é, por isso, que o bem-estar familiar almejado é sempre frustrante. O lucro não é para todos. Cito La Fontaine: "Perrette là-dessus saute aussi,transportée. / Le lait tombe; adieu veau, vache, cochon, couvée."

A sombra do 'Lamento borincano' me perseguia e continuava a me perseguir na leitura do primeiro capítulo de El laberinto de la soledad, de Octavio Paz. Naquele capítulo, 'El pachuco y otros extremos', encontraria as primeiras sementes dum ensaio que escreveria décadas mais tarde sob o título de 'O cosmopolitismo do pobre'". ${ }^{2}$

Volto a 1969. Admiro o colega Arcadio, como primeiro admirei e depois fui amigo do porto-riquenho Francisco (Paco) Pabón, quando o reencontro (ele também vinha de Rutgers University) na State University of New York at Buffalo. Eu estava contratado como Associate Professor with tenure pelo Departamento de Francês, e ele, no início da carreira, como Assistant Professor pelo Departamento de Espanhol e Português.

(No último departamento estava também a argentina Silvia Molloy que, posteriormente, fui encontrar como amiga de Arcadio em Princeton

\footnotetext{
${ }^{2}$ Cf.: "A diáspora é um processo social e cultural dramático, instaurando um mundo de cultura rural no meio de uma cidade como Nova York, coisa que hoje ocorre com mexicanos, guatemaltecos e outros que vêm direto de um mundo camponês" (A memória rota, 2016, p. 258 - grifo meu).
} 
e na New York University. Vejam como, no fundo, a admiração pode ir tecendo uma fascinante rede subterrânea de amizades que pouco a pouco sobe à tona. Dessa rede fará parte a querida amiga e grande admiradora da literatura brasileira que é Florencia Garramuño, hoje professora na Universidad de San Andrés, em Buenos Aires. Florencia teve a tese de doutorado sobre romancistas do cone sul, Genealogias culturales. Argentina, Brasil y Uruguai en la novela contemporánea, orientada por Arcadio. Da página de agradecimentos, retiro estas palavras para compor outra profunda rosa d'amigos que sobe à tona: "Arcadio Díaz-Quiñones, mi director de tesis, supo reconocer en los primeros balbuceos de este trabajo la 'gramática' con la cual se iría gestando este lenguaje; sin sus indicaciones bibliográficas y sus lecturas detenidas esta disertación habría seguido caminos tortuosos".).

Retomo. Pertencendo eu a departamento de prestígio, o de Literatura francesa em tempos pós-estruturalistas, ${ }^{3}$ tendo posição hierárquica superior à do jovem colega caribenho, fui imediatamente acionado por Paco Pabón que, infeliz junto aos hispanistas canônicos, não escondia a intenção de fundar um alternativo Puerto Rican Studies Center, à semelhança do Black Studies Center, que tinha sido criado dentro do American Studies Program, pioneiramente fundado, por sua vez, pelo professor Lawrence (Larry) Chisolm e, então, dirigido por ele. ${ }^{4}$

Das palavras de Arcadio desentranho o melhor perfil que eu poderia ter escrito de Francisco Pabón nos idos de 1969. Copio Arcadio e me lembro do amigo Paco:

\begin{abstract}
"Fui o primeiro de minha família, numerosíssima, a entrar na universidade. São realidades, não abstrações. [...] Os portoriquenhos da migração - e chegaria a nossa vez, porque toda a família migrava - não eram sequer um tema na universidade em que estudei. Tudo o que acontecia a meu redor e que me dizia respeito, ou que era muito próximo de mim e de minha família, não era assunto de discussão e reflexão, exceto por alguns estudos especializados" (p. 259).
\end{abstract}

\footnotetext{
${ }^{3}$ Era colega de Eugenio Donato, René Girard, Olga Bernal, John Simon, Raymond Federman, Thomas Kavanagh, Howard Bloch e tantos outros. Visitantes: Michel Foucault, Michel Serres, Roger Kempf, A. J. Greimas, etc. Em 1973, ocupei o posto de Acting Chairman do Departamento.

${ }^{4}$ Falecido em 1998, Larry é lembrado pelo colega Kerry S. Grant, Decano de Artes e Letras da Universidade, como "a pioneer in the development of critical approaches to American culture and social activism".
} 
Duas figuras importantes na governança da universidade vieram também em ajuda do porto-riquenho Paco. O decano de Artes e Letras, John P. Sullivan 5 , latinista de talento e especialista em Ezra Pound recémchegado do Reino Unido (via Texas) e disposto a abrir as portas do campus universitário aos coletivos representativos de minorias, e o professor Albert (Albie) Michaels ${ }^{6}$, nascido em Buffalo e figura influente na comunidade e no Departamento de História.

É indispensável assinalar que a ambição de Pabón ganha também realce pelo apoio que recebe do grupo de estudantes boricuas Young Lords, liderados em New York por Felipe Luciano. Formam o núcleo inicial de estudantes e de artistas que, daí a três anos, estará se encontrando e se reunindo no centro cultural Nyurican Poets Café, situado no Lower East Side de Manhattan. Retomo palavras de A memória rota para apresentar-lhes os Young Lords:

\footnotetext{
"Como disse o escritor cubano Manuel Moreno Fraginals, a primeira coisa que o escravo perde é o nome. [...] Os Young Lords e os Black Panthers são exemplos de uma conjunção entre armas e letras, quando os guerrilheiros nomeiam-se a si mesmos, para então intervir na vida pública" (p. 252).
}

Não há como não citar essas observações agudas de Arcadio sobre o modo como o desenvolvimento de Porto Rico se empilha em cima de camadas de frustração humana, econômica e ideológica: "Vendo retrospectivamente, ocorreram dois processos simultâneos. Um é o êxodo da população para Nova York depois da guerra, dirigido pelo Estado; o outro é o projeto de industrialização, ou seja, o abandono do campo. O mundo rural passa a debilitar-se, e as cidades começam a encher. A literatura (Julia de Burgos, José Luis González, Pedro Juan Soto, René Marqués, Luis Rafael Sánchez, Pedro Pietri e outros) acompanha esse processo, assim como os artistas gráficos. A palavra 'progresso' é central, como o foi em diversos outros países" (p. 259).

\footnotetext{
${ }^{5}$ Leia-se seu obituário no jornal New York Times. Disponível em: http://www.nytimes. com/1993/04/17/obituaries/john-p-sullivan-62-scholar-and-teacher.html. Acesso em 14 de maio de 2017.

${ }^{6}$ Um bom portrait do contraditório e fascinante Albie Michaels, escrito no ano de 2012, se encontra disponível em: http://artvoice.com/issues/v11n41/news_analysis.html. Acesso em 14 de maio de 2017.
} 
Em setembro de 1970, estava fundado o Puerto Rican Studies Center na SUNY at Buffalo. Seus primeiros professores foram Francisco Pabón (chairman), Alfredo Matilla Rivas (filho de conhecido músico espanhol, exilado em Porto Rico) e o ativista brasileiro Abdias do Nascimento, indicado por mim. Como primeiro Visiting Professor, chegou da ilha o grande romancista porto-riquenho Pedro Juan Soto, autor entre outros do aclamado romance Usmail.

A figura de Abdias - que depois de ocupar o posto de Full Professor na universidade se aposentou e regressou ao Brasil para se tornar senador da República, retomando a carreira de ativista negro na política nacional - era, estrategicamente, ferramenta importante na elaboração teórica do grupo dissidente do Departamento de Espanhol e Português.

Compartilham todos da convicção de que o estudo do Caribe e de suas diásporas - tão complexas do ponto de vista econômico, cultural e linguístico - se enriquece com o diálogo sobre a cultura e a história da América Latina e, em particular, com a história do Brasil, então sob a ditadura dos militares. O congraçamento foi tão feliz, que, mesmo sendo eu docente no Departamento de Francês, pudemos convidar ao campus de Buffalo figuras como Hélio Oiticica (apresentou-se na Albright-Knox Art Gallery no dia 27 de fevereiro de 1973) e Glauber Rocha (recebido pelo novo especialista em cinema, professor Gerald (Gerry) $\mathrm{O}^{\prime} \mathrm{Grady}^{7}$, ele apresenta seus filmes e fala a um auditório de uns 400 estudantes, tendo sido eu seu intérprete). Ali também foi encenada a peça Arena conta Zumbi, com o diretor Augusto Boal e atores do elenco original.

Chegado é o momento de citar versos do poeta porto-riquenho que mais me impressionou naqueles anos, Pedro Pietri, um "desquiciado", a viver como o mago Antonin Artaud, como dizia amorosamente meu colega e amigo Luis Mario Schneider. Seu longo poema, "Puerto Rican Obituary", lido em Buffalo numa das muitas vezes que por lá passou e publicado pela primeira vez na Monthly Review, em 19738, é inesquecível

\footnotetext{
${ }^{7}$ Para informação sobre o papel de Gerry em Buffalo e nos Estados Unidos da época, leia-se: https://www.burchfieldpenney.org/artists/artist:gerald-o-grady/. Acesso em 14 de maio de 2017.

${ }^{8}$ Por ocasião da sua morte em 2004, a revista que o lançou publica o obituário do próprio poeta, de que extraio este trecho:

"'Puerto Rican Obituary' was first read in 1969 at a rally in support of the Young Lords Party, an anti-imperialist Latino youth group in New York. Like the Black Panther Party,
} 
e será responsável pela atitude multilinguística iconoclasta (espécie de escrita à la Macunaíma, mas às avessas, já que com vistas ao cosmopolitismo da experiência política) que tomei ao escrever o romance Stella Manhattan. Neste, os idiomas se mesclam como se misturam as várias etnias e as várias nacionalidades na metrópole norte-americana, ou em qualquer metrópole do mundo moderno.

\author{
Juan \\ Miguel \\ Milagros \\ Olga \\ Manuel \\ All died yesterday today \\ and will die again tomorrow \\ passing their bill collectors \\ on to the next of kin \\ All died \\ waiting for the garden of eden \\ to open up again \\ under a new management \\ All died \\ dreaming about america \\ waking them up in the middle of the night \\ screaming: Mira Mira \\ your name is on the winning lottery ticket \\ for one hundred thousand dollars \\ All died \\ hating the grocery stores \\ that sold them make-believe steak \\ and bullet-proof rice and beans \\ All died waiting dreaming and hating
}

the Young Lords were community activists, supporting demands for fair and affordable housing and decent health care, and they ran free breakfast programs for children. They linked their neighborhood militancy to a program that called for the end of U.S. imperial adventurism in Vietnam and elsewhere, third world liberation, an end to the oppression of the poor and people of color, and the building of a socialist society. The Young Lords were destroyed by U.S. government provocations in the mid 1970s, but Pedro Pietri continued on as a radical activist and poet-he saw no distinction between these roles. Most notably he helped to found and sustain the Nuyorican Poets Café, an acclaimed center for oppositional arts and literature". 
Já falei demais. Peço-lhes desculpas pelo palavrório que a memória diz poderia ser infindável. O bom-senso recomenda, no entanto, atitude a ser tomada metaforicamente, apenas metaforicamente, a Camões:

Não mais, Musa, não mais que a Lira tenho

Destemperada e a voz enrouquecida.

Permitam-me que cale a voz da memória - rota - com estes versos premonitórios de Os Lusíadas:

$\mathrm{O}$ favor com que mais se acende o engenho

Não no dá a pátria, não, que está metida

No gosto da cobiça e na rudeza

Duma austera, apagada e vil tristeza.

\section{Recebido em}

maio de 2017

Aprovado em

junho de 2017 